\title{
Animal cognition: an integrative approach
}

\author{
Debbie M. Kelly ${ }^{1}$
}

Published online: 14 December 2017

○) Springer-Verlag GmbH Germany, part of Springer Nature 2017

Since its establishment in 1998, Animal Cognition has built a strong reputation as an interdisciplinary journal of excellence, offering the latest innovative and rigorous research exploring animal cognition within an evolutionary framework. This foundation was established from the first issue under the guidance of Dr. Tatiana Czeschlik as Founding Editor. From 2011 to 2016, Dr. Stephen Lea further strengthened and broadened the scope of the journal. In his Editorial piece, Dr. Lea applauded the field for its establishment as a central area in the study of animal sciences and noted the role Animal Cognition has played in the success of the discipline. Now I am honored to take on the opportunity to lead Animal Cognition, surrounded by a team of outstanding and respected research scientists: Drs. Christian Agrillo (University of Padova), Kim Bard (University of Portsmouth), Ken Cheng (Macquarie University), Jeffrey Katz (Auburn University) Stephen Lea (University of Exeter), and Monique Udell (Oregon State University). These leading experts bring with them an exceptional breadth and depth of knowledge necessary to meet the growing questions and methodologies used for the study of animal cognition. Over the first year, my editorial team and I continued with the challenges set out by Drs. Czeschlik and Lea to publish and showcase the excellent research being conducted in the area of animal cognition. We will continue to encourage a broad range of research topics and endeavor to forge new paths to understand underrepresented species and taxonomic groups. As the editorial team of a leading interdisciplinary journal of animal cognition, we aspire to represent the full range of our field.

As pointed out by Dr. Lea, in following the guidance of Tinbergen (1963), we need to strive to address all four questions, or levels of analysis, to develop a complementary study of animal behavior: the function, phylogeny, mechanism and ontogeny. Developments in technology will

Debbie M. Kelly

animal.cognition.editor@umanitoba.ca

1 University of Manitoba, Winnipeg, MB, Canada undoubtedly influence the types of questions we may ask and the approaches afforded to address these issues. As just a couple of examples, we are witnessing smaller, more powerful and economically feasible technologies permitting the study of animal cognition in natural settings and from novel perspectives. This approach has allowed our field to better understand the function of animal cognition and to ask questions pertaining to phylogenetic history. Furthermore, the exemplary rate in the development of molecular techniques will allow us ask more sophisticated questions about the mechanisms underlying cognition, such as those investigated in areas of behavioral genetics. However, there is still considerable need to further our understanding of ontogeny or development in our research. Striving for a truly integrated approach, using these four levels of complementary inquiry, will no doubt foster our understanding of animal cognition. In the spirit that has always been at the core of Animal Cognition, such novel approaches and groundbreaking ideas, set within experimental rigor, will continue to be the represented in the journal. We invite our readers, contributors and board members to push the boundaries of what is known with the goal of advancing our science.

Animal Cognition will continue to be the source of innovative, rigorous and original reports on the recent developments in the field. Our focus will remain on empirical reports, but we encourage submissions of short communications, review articles and correspondences. Furthermore, we are constantly striving to be on the cutting edge of recent developments and important findings. Thus, we encourage submissions for dedicated Special Issues to delve deeper into topics of emerging importance.

This year, we will celebrate the 20th anniversary of Animal Cognition. I look forward to the challenges and rewards the coming years will bring, and I'm excited to be part of the discoveries and insights awaiting us as we continue our quest to understand animal cognition.

Debbie M. Kelly

Editor-in-Chief 


\section{Reference}

Tinbergen N (1963) On aims and methods of ethology. Z Tierpsychol 20:410-433. https://doi.org/10.1163/157075605774840941 